DOI: $10.26418 /$ positron.v11i1.44052

\title{
Analisis Kurva Dose Volume Histogram (DVH) pada Teknik 3D Konformal dengan Metode Monte Carlo
}

\author{
Sitti Yania* \\ aDepartemen Fisika, Fakultas Matematika dan Ilmu Pengetahuan Alam, Institut Pertanian Bogor, Jalan \\ Meranti Kampus IPB Dramaga, Bogor, Jawa Barat 16680 \\ *Email : sittiyani@apps.ipb.ac.id
}

(Diterima 26 Desember 2020; Disetujui 18 Juli 2021; Dipublikasikan 15 Oktober 2021)

\begin{abstract}
Abstrak
Pemilihan sudut penyinaran yang tepat dalam terapi 3D konformal beberapa jenis kanker sangat menentukan keberhasilan pengobatan. Oleh karena itu, tujuan penelitian ini adalah untuk menganalisis dose volume histogram (DVH) teknik 3D konformal dengan konfigurasi sudut penyinaran yang berbeda pada fantom inhomogenitas dengan metode Monte Carlo (MC). EGSnrc-DOSXYZnrc MC digunakan untuk menyimulasikan teknik 3D konformal pada fantom inhomogenitas. Fantom inhomogenitas terdiri atas material air dan paru-paru dimana material paru-paru berada di dalam fantom air pada kedalaman $2 \mathrm{~cm}$ dari permukaan fantom air. Fantom ini diradiasi dengan sumber radiasi monoenergetik $10 \mathrm{MeV}$ dengan sudut penyinaran $0-360^{\circ}$. Data distribusi dosis yang diperoleh diolah untuk memperoleh data DVH. Analisis DVH juga dilakukan dengan mengkombinasikan beberapa sudut penyinaran dan pembobotan. Hasil yang diperoleh menunjukkan bahwa distribusi dosis hasil simulasi beragam terhadap sudut penyinaran. Dari kurva DVH diperoleh bahwa sudut penyinaran pada $0^{\circ}, 20^{\circ}, 40^{\circ}, 320^{\circ}$, dan $340^{\circ}$ dengan pembobotan memberikan kurva DVH target yang paling baik dibandingkan dengan set-up sudut penyinaran lainnya. Pembobotan dapat mereduksi dosis pada resiko organ dan meningkatkan dosis pada target.
\end{abstract}

Kata kunci: 3D konformal, DVH, EGSnrc-DOSXYZnrc, monte carlo

\section{Latar Belakang}

Secara umum, tujuan pengobatan kanker dengan radioterapi adalah untuk memberikan dosis maksimum kepada target dan dosis minimum pada risiko organ (organ at risk/OAR). Salah satu teknik penyinaran dalam radioterapi adalah threedimensional conformal radiation therapy (3D-CRT). Teknik ini masih banyak diaplikasikan pada beberapa kasus pengobatan kanker seperti kanker payudara [1,2] dan kanker prostat [3]. Pemilihan sudut penyinaran merupakan salah satu langkah yang sangat penting dalam perencanaan pengobatan. Dalam aplikasi klinis, langkah ini dilakukan secara manual berdasarkan pengalaman pembuat perencanaan. Langkah ini membutuhkan waktu yang relatif lama bergantung pada posisi target dan OAR. Beberapa algoritma telah dikembangkan untuk mempermudah penentuan sudut penyinaran dan waktu perencanaan pengobatan yang lebih cepat $[4,5]$. Optimasi sudut penyinaran yang tepat dapat dilakukan dengan menggunakan pembobotan sudut berkas yang bergantung pada posisi target dan OAR [6].

Metode MC dapat digunakan untuk memperoleh sudut berkas dan pembobotan yang optimal dalam 3D-CRT. Salah satu perangkat lunak yang memanfaatkan metode MC adalah EGSnrc. Perangkat lunak ini telah digunakan menyimulasikan teknik penyinaran yang lebih kompleks dibandingkan dengan 3D-CRT pada fantom homogen dan inhomogen yakni teknik intensity modulated radiation therapy (IMRT) $[7,8]$. Distribusi dosis 3 dimensi (3D) dapat dihasilkan melalui simulasi dengan EGSnrc. Analisis dosis dapat dilakukan dengan 3 cara yakni analisis 1 dimensi (percent depth dose/PDD dan profil dosis), 2 dimensi (kurva isodosis) dan 3 dimensi (dose volume histogram/DVH dan gamma index). Dalam penelitian ini dilakukan analisis dosis 3 dimensi yakni DVH. DVH merepresentasikan nilai dosis rata-rata yang diterima oleh organ atau target tertentu dalam perencanaan pengobatan 3D. Kurva ini pada umumnya dioptimasi dengan melakukan pembobotan sudut penyinaran. Optimasi pembobotan sudut penyinaran melalui simulasi MC sangat mudah dan sederhana untuk diterapkan pada fantom yang kompleks.

Oleh karena itu, penelitian ini bertujuan untuk menganalisis DVH teknik pengobatan kanker 3D konformal pada fantom inhomogenitas dengan 
menggunakan metode Monte Carlo. Selain itu, dalam penelitian ini diperkenalkan algoritma baru dengan menggunakan bahasa pemrograman MATLAB yang dapat digunakan untuk menjumlahkan beberapa data 3ddose keluaran dari DOSXYZnrc dan membentuk kurva DVH untuk masing-masing struktur yang didefinisikan.

\section{Metodologi}

Tahapan simulasi terdiri atas penentuan set-up simulasi, simulasi dengan EGSnrc-DOSXYZnrc, analisis data distribusi dosis (data 3ddose), dan perhitungan DVH dengan dilakukan pembobotan dan tidak dilakukan pembobotan.

\subsection{Set-up Simulasi}

Simulasi dilakukan di dalam fantom inhomogenitas yang berisi material air dan paruparu. Dimensi material ini masing-masing adalah 40x40x40 $\mathrm{cm}^{3}$ dan 0,5x0,5x0,5 $\mathrm{cm}^{3}$ (Gambar 1). Densitas dan karakteristik material yang digunakan memanfaatkan data yang telah disediakan oleh perangkat lunak berupa data cross section. Inhomogenitas berupa material paru-paru ini diletakkan $2 \mathrm{~cm}$ dari permukaan fantom. Titik koordinat 0,0,0 berada di salah satu permukaan fantom air yang dekat dengan posisi paru-paru. Sumber yang digunakan adalah berkas monoenergetik berupa partikel foton dengan energi $10 \mathrm{MeV}$. Source to surface distance (SSD) yang diaplikasikan adalah $100 \mathrm{~cm}$. Distribusi dosis diukur untuk ukuran medan paparan $5 \times 5 \mathrm{~cm}^{2}$ dan $10 \times 10 \mathrm{~cm}^{2}$ pada beberapa sudut penyinaran, yakni $0^{\circ}, 20^{\circ}, 25^{\circ}, 40^{\circ}, 9^{\circ}, 180^{\circ}, 270^{\circ}, 315^{\circ}, 320^{\circ}, 330^{\circ}$, $340^{\circ}$, dan $355^{\circ}$. Setiap simulasi dengan satu sudut penyinaran diperoleh satu data simulasi. Oleh karena itu, jumlah data yang diperoleh adalah perkalian jumlah ukuran medan paparan dengan jumlah sudut penyinaran yakni 24 data. Sudut teta dan pi dalam simulasi diatur sehingga memperoleh sudut berkas sesuai dengan yang diinginkan. Transformasi koordinat sudut teta dan pi dilakukan untuk memperoleh sudut penyinaran yang tepat berdasarkan pada manual DOSXYZnrc [10].

\subsection{EGSnrc (Electron Gamma Shower)}

EGSnrc merupakan perangkat lunak yang menggunakan metode Monte Carlo dalam menyimulasikan radiasi pengion yang melewati suatu materi. Perangkat lunak ini dapat menyimulasikan perjalanan foton, elektron dan positron dengan energi kinetik antara $1 \mathrm{keV}$ dan 10 $\mathrm{GeV}$ dalam material homogen maupun inhomogen. EGSnrc diperkenalkan pada tahun 2000 yang dikembangkan dari perangkat lunak Electron Gamma Shower (EGS) yang diperkenalkan oleh Stanford Linear Accelerator Center (SLAC) pada tahun 1970-an [9].

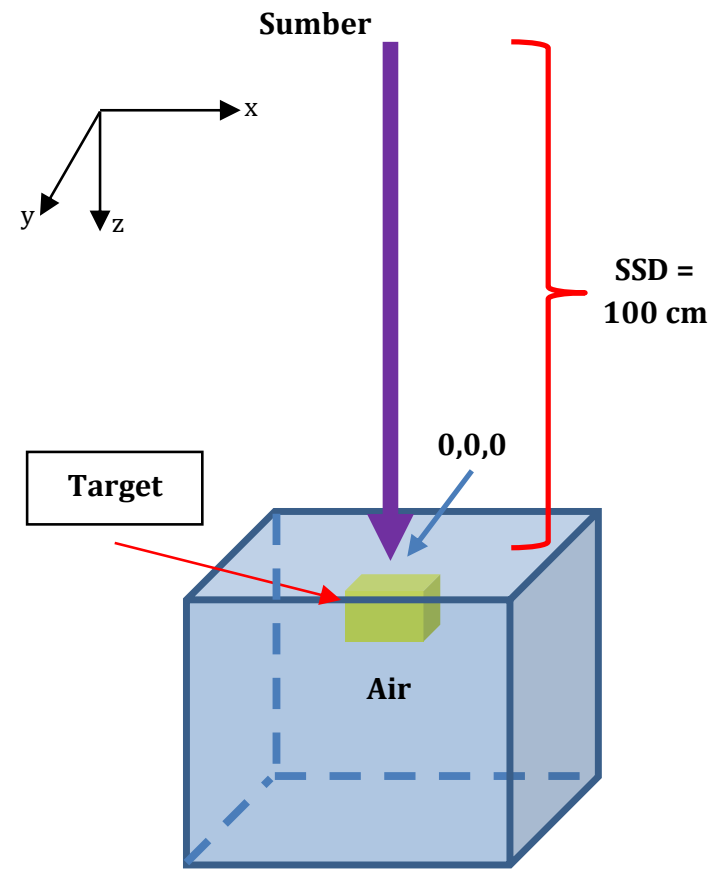

Gambar 1. Pengaturan simulasi

EGSnrc dilengkapi dengan dua perangkat lunak tambahan yakni BEAMnrc dan DOSXYZnrc yang masing-masing berfungsi untuk memodelkan kepala pemercepat partikel (head linear accelerator) dan menyimulasikan distribusi dosis pada fantom virtual. Fantom virtual yang didefinisikan dapat berupa fantom yang berisi material yang didefinisikan sendiri maupun berasal dari data gambar computed tomography (CT) dimana masing-masing voxel memuat data Hounsfield Unit (HU) material yang bersesuaian [10].

Parameter simulasi didefinisikan sesuai dengan kondisi standar eksperimen. Energi ambang elektron dan foton diatur pada nilai ECUT = $521 \mathrm{keV}$ untuk elektron dan PCUT =10 keV untuk foton. Jumlah partikel yang disimulasikan adalah $3 \times 10^{8}$ partikel foton dengan energi yang seragam. Voxel dalam arah $\mathrm{x} y$, dan $\mathrm{z}$ memiliki ukuran yang sama untuk semua simulasi. 


\begin{tabular}{|cccccc|}
\hline 80 & 80 & 80 & & & \\
-20.000000 & -19.500000 & -19.000000 & -18.500000 & -18.000000 & -17.500000 \\
-20.000000 & -19.500000 & -19.000000 & -18.500000 & -18.000000 & -17.500000 \\
0.0000000 & 0.50000000 & 1.0000000 & 1.5000000 & 2.0000000 & 2.5000000 \\
$6.80023717344149558 \mathrm{E}-015$ & $4.80005648128669602 \mathrm{E}-015$ & $4.05187818598748919 \mathrm{E}-015$ & $5.84777373231180429 \mathrm{E}-015$ \\
$8.54465441830299346 \mathrm{E}-015$ & $5.85802996553226364 \mathrm{E}-015$ & $7.70651247692014288 \mathrm{E}-015$ & $7.36832791178923666 \mathrm{E}-015$ \\
$1.05211870153891599 \mathrm{E}-014$ & $9.21111178023159968 \mathrm{E}-015$ & $1.10025882046470927 \mathrm{E}-014$ & $1.08110649125157288 \mathrm{E}-014$ \\
$1.20325907733790991 \mathrm{E}-014$ & $1.14223589014696288 \mathrm{E}-014$ & $1.30411430185791714 \mathrm{E}-014$ & $1.29375678659018302 \mathrm{E}-014$ \\
$1.37541957241373058 \mathrm{E}-014$ & $1.44061058103558245 \mathrm{E}-014$ & $1.53910014048839144 \mathrm{E}-014$ & $1.63274500806241813 \mathrm{E}-014$ \\
$1.55485693406633463 \mathrm{E}-014$ & $1.54874385362045497 \mathrm{E}-014$ & $1.71556901333586424 \mathrm{E}-014$ & $1.70817444610156803 \mathrm{E}-014$ \\
$1.86536628163183875 \mathrm{E}-014$ & $1.45134492988990879 \mathrm{E}-014$ & $1.77480996649661932 \mathrm{E}-014$ & $1.40671311759965302 \mathrm{E}-014$ \\
$1.47648630367083612 \mathrm{E}-014$ & $1.41312841454862369 \mathrm{E}-014$ & $1.43536302209144378 \mathrm{E}-014$ & $1.10415600982822312 \mathrm{E}-014$ \\
$1.27288231627514524 \mathrm{E}-014$ & $1.39348482055409116 \mathrm{E}-014$ & $1.30714683546526705 \mathrm{E}-014$ & $1.05020992606108293 \mathrm{E}-014$ \\
$1.21242430816739165 \mathrm{E}-014$ & $8.68855212956811991 \mathrm{E}-015$ & $6.94503658418824198 \mathrm{E}-015$ & $9.05248030147384606 \mathrm{E}-015$ \\
$6.87936265249825952 \mathrm{E}-015$ & $9.03507117644323847 \mathrm{E}-015$ & $6.72043356096683619 \mathrm{E}-015$ & $5.97526739823508725 \mathrm{E}-015$ \\
$4.71465750422124246 \mathrm{E}-015$ & $4.79055930323248261 \mathrm{E}-015$ & $4.35554033141348778 \mathrm{E}-015$ & $5.09097790739089475 \mathrm{E}-015$ \\
& & & & & \\
0.20662136358504618 & 0.18782942292573879 & 0.18143031768157059 & 0.19360033951909897 \\
0.17340386155620482 & 0.19777519832690590 & 0.15541108549148863 & 0.15081855375359124 \\
0.15027055267590594 & 0.16223193764839033 & 0.14144580174884300 & 0.14914754062417965 \\
0.13533423141568904 & 0.13587780333953836 & 0.13876676236435334 & 0.13195606794731821 \\
0.12635384992582208 & 0.12222479008185408 & 0.11805671952133964 & 0.12421276606145350 \\
0.13064580166921039 & 0.11418922217551133 & 0.12161547545762506 & 0.11783747698097956 \\
\hline
\end{tabular}

Gambar 2. Struktur data 3ddose

\subsection{Perhitungan DVH}

Dalam simulasi Monte Carlo dengan EGSnrcDOSXYZnrc diperoleh data distribusi dosis dalam 3 dimensi yang tersimpan dalam file dengan ekstensi 3ddose. Struktur data dari data 3ddose seperti diperlihatkan pada Gambar 2. Data ini terdiri atas 6 baris data yakni jumlah voxel dalam arah $\mathrm{x}, \mathrm{y}$, dan $\mathrm{z}$; posisi voxel dalam arah $\mathrm{x}$; posisi voxel dalam arah $\mathrm{y}$; posisi voxel dalam arah z, nilai dosis dalam cGy, dan eror dosis. Data ini diekstrak dengan menggunakan MATLAB untuk membaca data distribusi dosis yang berada pada baris nilai dosis.

Setiap simulasi dengan satu sudut penyinaran akan diperoleh satu data distribusi dosis. Kurva DVH dibentuk dari gabungan beberapa sudut penyinaran sehingga data 3ddose yang diperoleh dari beberapa simulasi digabungkan dan dijumlahkan menjadi satu menggunakan bahasa pemrograman MATLAB. Dalam penelitian ini, kami memperkenalkan algoritma baru yang dapat digunakan untuk menjumlahkan dua atau lebih data 3ddose yang diperoleh dari simulasi dengan DOSXYZnrc. Selain itu, algoritma ini juga dapat menghasilkan kurva DVH untuk masing-masing struktur yang didefinisikan dalam fantom. Dalam simulasi ini terdapat dua struktur yakni OAR dan target.

Kurva DVH target dan OAR untuk masingmasing sudut penyinaran dianalisis dan dibandingkan untuk memperoleh konfigurasi sudut penyinaran dan pembobotan yang paling baik. Faktor bobot tidak disertakan dalam simulasi. Pembobotan dilakukan ketika penggabungan distribusi dosis.

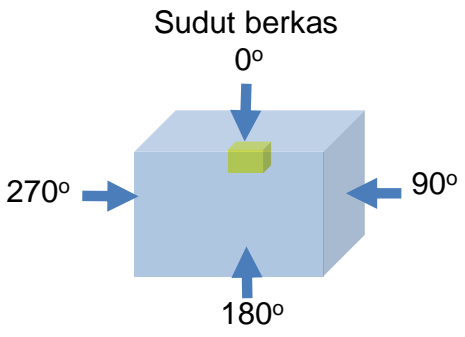

(a)

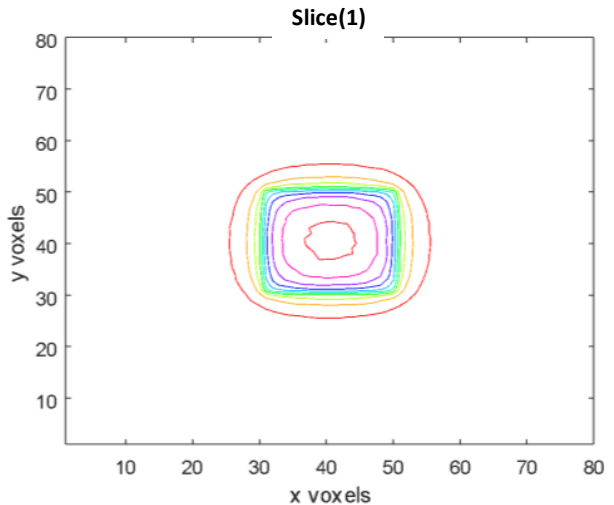

(b) 


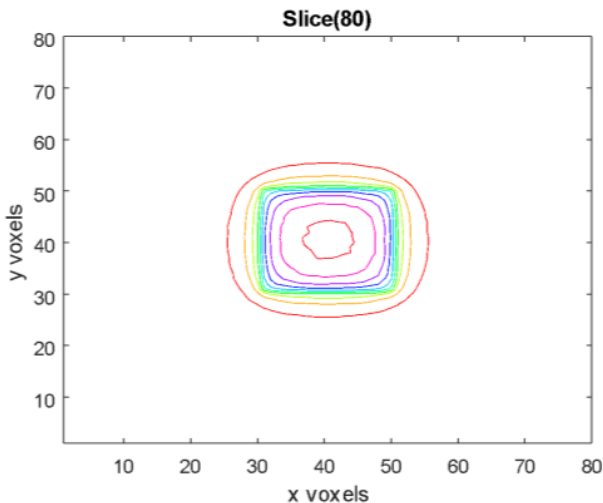

(c)

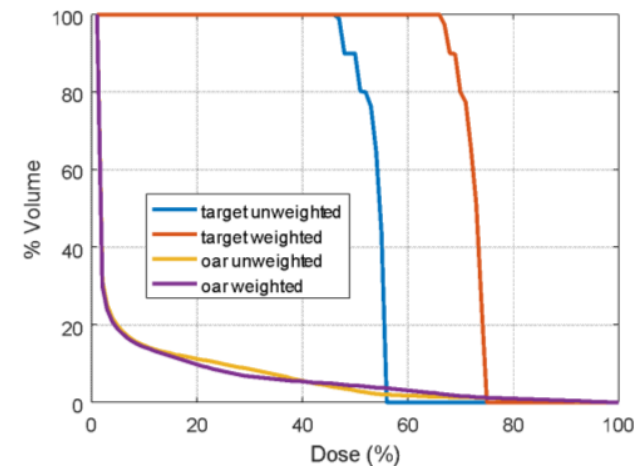

(d)

Gambar 3. (a) Konfigurasi sudut penyinaran set-up 1, (b) kurva isodosis slice 1, (c) kurva isodosis slice 80, dan (d) Kurva DVH set-up 1 (Keterangan: unweighted = tanpa pembobotan, dan weighted = dengan pembobotan).

\section{Hasil}

Berikut perbandingan kurva isodosis dan DVH pada tiga konfigurasi sudut penyinaran. Konfigurasi sudut ini dipilih berdasarkan posisi target yang didefinisikan dalam set-up simulasi. Analisis DVH

dilakukan dengan dua acara yakni dengan melakukan pembobotan (weighted) dan tidak melakukan pembobotan (unweighted).

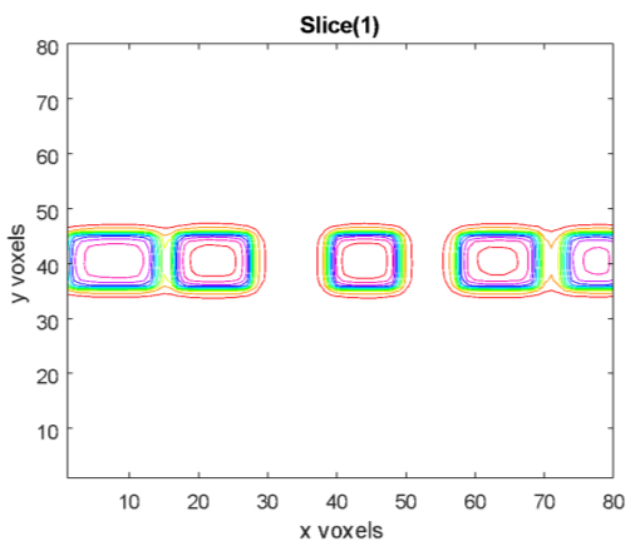

(a)

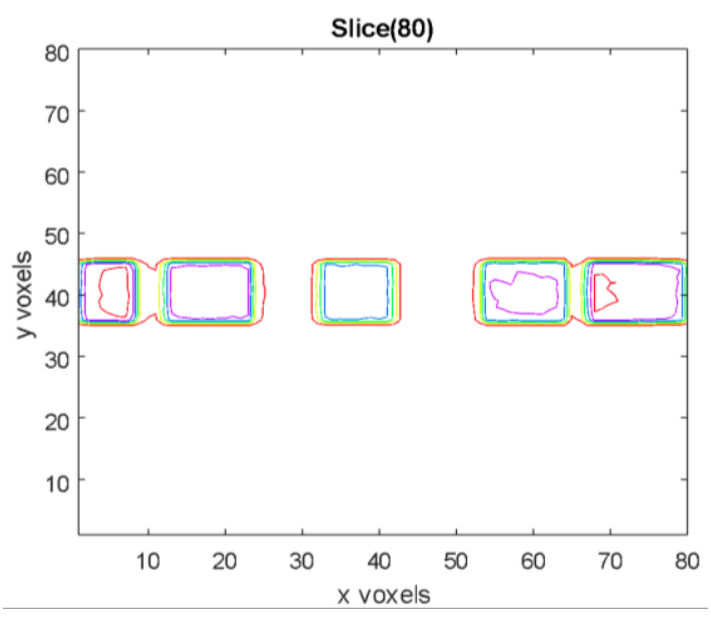

(c)

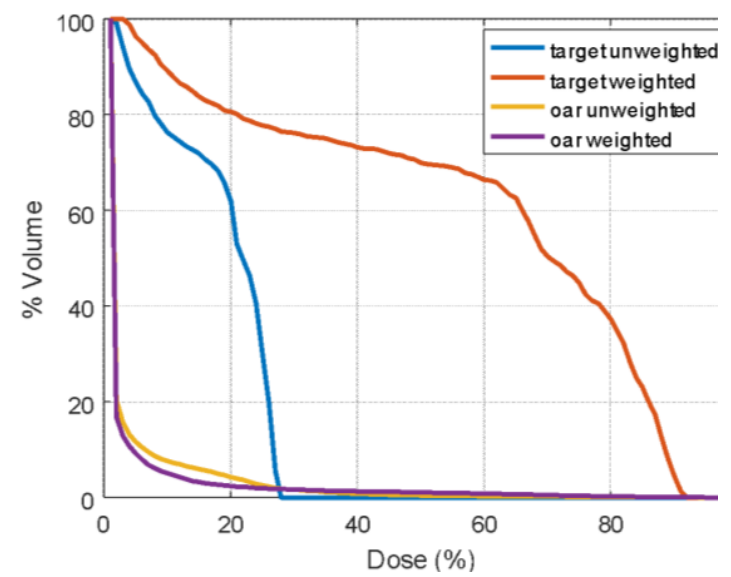

(d)

Gambar 4. (a) Konfigurasi sudut penyinaran set-up 2, (b) kurva isodosis slice 1, (c) kurva isodosis slice 80, dan (d) Kurva DVH set-up 2

Untuk set-up 1, sudut penyinaran dipilih pada $0^{\circ}, 90^{\circ}, 180^{\circ}$, dan $270^{\circ}$. Gambar 3(a) menunjukkan konfigurasi sudut penyinaran. Bentuk kurva isodosis pada slice 1 dan 80 ditunjukkan pada 
Gambar 3 (b) dan (c). Slice merupakan potongan penampang lintang dari fantom yang terdiri atas 80 potongan pada setiap fantom. Pemotongan dilakukan dalam arah + z. Karena ukuran fantom 40 $\mathrm{cm}$ dalam arah $\mathrm{z}$, maka ketebalan masing-masing slice adalah $0,5 \mathrm{~cm}$. Setiap slice memiliki ukuran $40 \times 40 \times 0,5 \mathrm{~cm}^{3}$. Kurva ini memiliki bentuk yang serupa karena dalam simulasi yang dilakukan tidak dilakukan pembobotan. Kurva DVH yang ditunjukkan pada Gambar 3(d) merepresentasikan bahwa dosis yang diterima oleh target dengan pembobotan lebih banyak dibanding dengan tanpa pembobotan dengan perbedaan sekitar 20\% volume. Sedangkan pada DVH OAR memiliki nilai yang relatif sama untuk yang diboboti dan yang tidak diboboti.

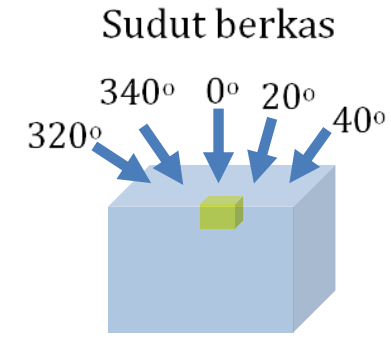

(a)

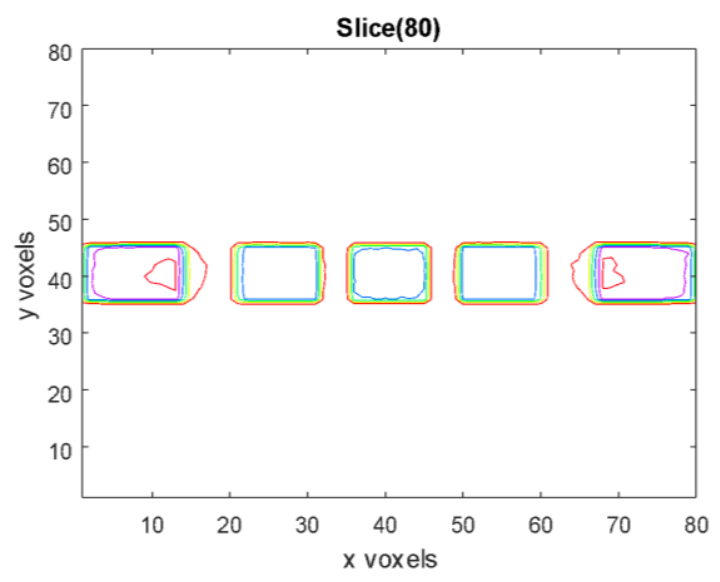

(c)
Pada set-up 2, sudut penyinaran dipilih pada

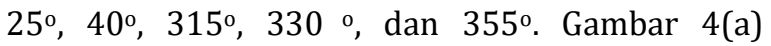
menunjukkan konfigurasi sudut penyinaran. Bentuk kurva isodosis pada slice 1 dan 80 ditunjukkan pada Gambar 4(b) dan (c). Kurva ini memiliki bentuk yang berbeda karena pada simulasi set-up 2 , sudut penyinaran berada di salah satu sisi fantom sehingga dosis yang terdeposisi pada slice 1 lebih besar dibanding pada slice 80 yang jauh dari sumber radiasi. Kurva DVH pada pengaturan sudut penyinaran ini ditunjukkan pada Gambar 4(d). Kurva ini merepresentasikan bahwa dosis yang diterima oleh target yang diboboti lebih banyak dibanding dengan yang tidak diboboti dengan perbedaan sekitar $60 \%$ volume. Sementara itu, kurva DVH OAR memiliki perbedaan kurang dari $5 \%$ volume.

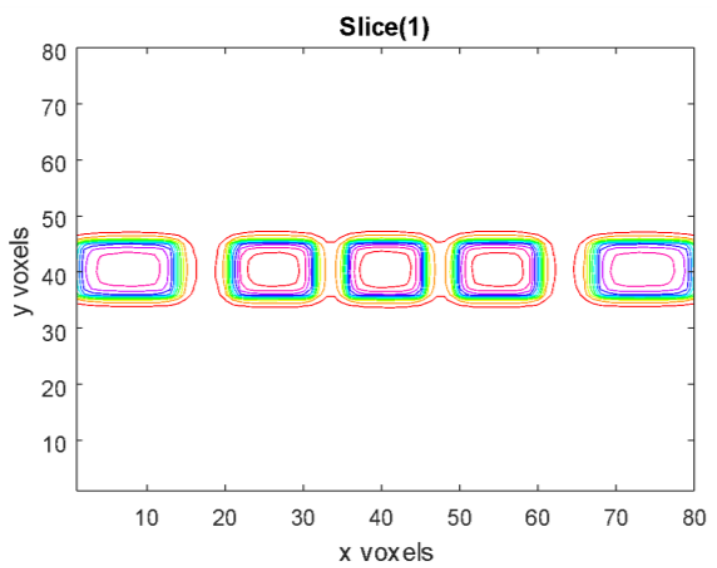

(b)

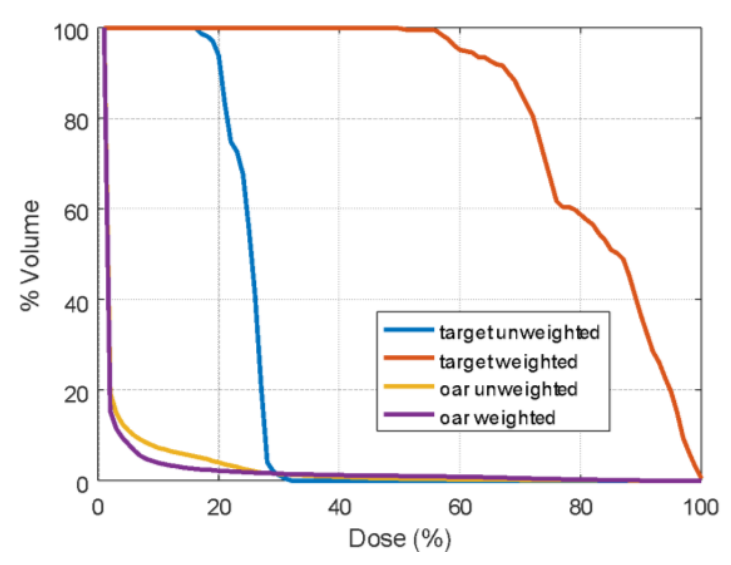

(d)

Gambar 5. (a) Konfigurasi sudut penyinaran set-up 3, (b) kurva isodosis slice 1, (c) kurva isodosis slice 80, dan (d) Kurva DVH set-up 3.

Pada set-up 3, sudut penyinaran dipilih pada $0^{\circ}, 20^{\circ}, 40^{\circ}, 320^{\circ}$, dan $340^{\circ}$. Gambar $5(\mathrm{a})$ menunjukkan konfigurasi sudut penyinaran pada set-up ini. Bentuk kurva isodosis pada slice
1 dan 80 ditunjukkan pada Gambar 5(b) dan (c). Kurva ini memiliki bentuk yang berbeda karena distribusi dosis yang dihasilkan sangat bergantung pada posisi sumber terhadap slice 
(permukaan) yang ditinjau. Semakin jauh dari sumber radiasi, maka dosis yang terdeposisi juga akan semakin kecil. Kurva DVH pada pengaturan sudut penyinaran ini ditunjukkan pada Gambar 5(d). Kurva ini merepresentasikan bahwa dosis yang diterima oleh target terboboti lebih besar dibanding dengan yang tidak terboboti dengan perbedaan sekitar $70 \%$ volume. Sementara itu, kurva DVH OAR memiliki perbedaan kurang dari $5 \%$ volume.

\section{Pembahasan}

Dalam penelitian ini dipilih tiga pengaturan sudut berkas yang berbeda-beda untuk memperoleh nilai DVH. Pemilihan sudut berkas didasarkan pada posisi target. Kurva DVH memberikan informasi besarnya dosis yang diterima oleh volume tertentu. Nilai dosis yang dianalisis pada setiap simulasi dinormalisasi terhadap nilai dosis maksimum untuk masingmasing konfigurasi sudut penyinaran. Pada sudut penyinaran $0^{\circ}, 20^{\circ}, 40^{\circ}, 320^{\circ}$, and $340^{\circ}$, lebih dari $70 \%$ target menerima dosis lebih dari $80 \%$ dari dosis keseluruhan. DVH OAR untuk sudut penyinaran $0^{\circ}, 20^{\circ}, 40^{\circ}, 320^{\circ}$, and $340^{\circ}$ menunjukkan nilai yang lebih baik dari pengaturan sudut yang lainnya ketika dilakukan pembobotan.

Dari kurva DVH untuk set-up 1, 2, dan 3 menunjukkan bahwa optimasi dengan pembobotan memberikan nilai DVH yang baik untuk target dimana kurva DVH bergeser kearah dosis yang lebih tinggi yang memungkinkan target memperoleh dosis yang besar yang dapat membunuh sel target tersebut. Selain itu, pembobotan berkas mengurangi dosis pada OAR. Wu dkk (2000) juga memperoleh hasil yang sama yang menunjukkan pentingnya pemilihan algoritma pembobotan yang tepat untuk memperoleh konfigurasi sudut penyinaran yang paling baik [6].

\section{Kesimpulan}

Dalam penelitian ini diperoleh bahwa pembobotan dalam 3D-CRT sangat penting dalam memperoleh kurva DVH untuk target dan OAR yang sesuai dengan tujuan pengobatan dengan radioterapi. Perbedaan DVH pada target sangat dipengaruhi oleh pembobotan untuk semua konfigurasi sudut penyinaran yang digunakan dalam penelitian ini. Pembobotan berkas berguna untuk mereduksi dosis pada OAR dan meningkatkan dosis pada target.

Penelitian ini akan dilanjutkan dengan menganalisis kurva DVH untuk teknik penyinaran yang lebih rumit yakni intensity modulated radiotherapy (IMRT) dan volumetric modulated arc therapy (VMAT).

\section{Daftar Pustaka}

[1] Mollah, A. S. and Sharmin, M. N., Dosimetric Comparison of Different 3DCRT Techniques in Left Breast Cancer Radiotherapy Planning, Bangladesh Journal of Nuclear Medicine, 17(2), pp.108-113, 2016.

[2] Xie, X., Ouyang, S., Wang, H., Yang, W., Jin, H., $\mathrm{Hu}, \mathrm{B}$. and Shen, L., Dosimetric comparison of left-sided whole breast irradiation with 3DCRT, IP-IMRT and hybrid IMRT, Oncology Reports, 31(5), pp.2195-2205, 2014.

[3] Shawata, A. S., Akl, M. F., Elshahat, K. M., Baker, N. A. and Ahmed, M. T., Evaluation of different planning methods of 3DCRT, IMRT, and RapidArc for localized prostate cancer patients: planning and dosimetric study, Egyptian Journal of Radiology and Nuclear Medicine, 50(1), 2019.

[4] Gizyńska, M. K. and Kukołowicz, P. F., Dose gradient based algorithm for beam weights selection in 3D-CRT plans, Reports of Practical Oncology and Radiotherapy, 19(S), pp.10-13, 2014.

[5] Jabbari, K., Azarmahd, N., Babazade, S. and Amouheidari, A., Optimizing of the Tangential Technique and Supraclavicular Fields in 3 Dimensional Conformal Radiation Therapy for Breast Cancer, Journal of Medical Signals and Sensors, 3(2), pp.107-116, 2013.

[6] Wu, X., Zhu, Y., Dai, J. and Wang, Z., Selection and determination of beam weights based on genetic algorithms for conformal radiotherapy treatment planning, Physics in Medicine and Biology, 45(9), pp.2547-2558, 2000.

[7] Yani, S., Budiansah, I., Kamirul, Rhani, M. F. and Haryanto, F., Study of efficiency in fivefield and field-by-field intensity modulated radiation therapy (IMRT) plan using DOSXYZnrc Monte Carlo code, Reports of Practical Oncology and Radiotherapy, 25(3), 2020.

[8] Yani, S., Rizkia, I., Kamirul, Rhani, M. F., Haekal, M. and Haryanto, F., EGSnrc application for IMRT planning, Reports of Practical Oncology and Radiotherapy, 25(2), 2020.

[9] Kawrakow, I., Mainegra-Hing, E., Rogers, D. W. O., Tessier, F. and Walters, B. R. B., The EGSnrc 
POSITRON Vol. 11, No. 1 (2021), Hal. 19 - 25

code system: Monte Carlo simulation of electron and photon transport NCR Report PIRS-701 (Ottawa: National Research Council of Canada), pp.2001-2006, 2013.
[10] Walters, B., Kawrakow, I. and Rogers, D. W. O., DOSXYZnrc Users Manual, pp.1-125, 2013. 